\title{
Medulloblastoma in the Molecular Era
}

\author{
Claudia Miranda Kuzan-Fischer, M.D., ${ }^{1,2 *}$ Kyle Juraschka, M.D., ${ }^{1-5 *}$ Michael D. Taylor, M.D., Ph.D. ${ }^{1-5}$ \\ Developmental \& Stem Cell Biology Program, 'The Hospital for Sick Children, Toronto, Canada \\ The Arthur and Sonia Labatt Brain Tumour Research Centre, ${ }^{2}$ The Hospital for Sick Children, Toronto, Canada \\ Department of Surgery, ${ }^{3}$ University of Toronto, Toronto, Canada \\ Department of Laboratory Medicine and Pathobiology, ${ }^{4}$ University of Toronto, Toronto, Canada \\ Division of Neurosurgery, ${ }^{5}$ University of Toronto, Toronto, Canada
}

Medulloblastoma is the most common malignant brain tumor of childhood and remains a major cause of cancer related mortality in children. Significant scientific advancements have transformed the understanding of medulloblastoma, leading to the recognition of four distinct clinical and molecular subgroups, namely wingless (WNT), sonic hedgehog, group 3, and group 4. Subgroup classification combined with the recognition of subgroup specific molecular alterations has also led to major changes in risk stratification of medulloblastoma patients and these changes have begun to alter clinical trial design, in which the newly recognized subgroups are being incorporated as individualized treatment arms. Despite these recent advancements, identification of effective targeted therapies remains a challenge for several reasons. First, significant molecular heterogeneity exists within the four subgroups, meaning this classification system alone may not be sufficient to predict response to a particular therapy. Second, the majority of novel agents are currently tested at the time of recurrence, after which significant selective pressures have been exerted by radiation and chemotherapy. Recent studies demonstrate selection of tumor sub-clones that exhibit genetic divergence from the primary tumor, exist within metastatic and recurrent tumor populations. Therefore, tumor resampling at the time of recurrence may become necessary to accurately select patients for personalized therapy.

Key Words : Medulloblastoma · Pediatrics · Neurosurgery · Neoplasms · Computational biology.

\section{INTRODUCTION}

Medulloblastomas are heterogeneous, highly aggressive tumors of the central nervous system and are the most frequent malignant brain tumors in children ${ }^{14,16,67)}$. Most medulloblastomas are sporadic and arise in the posterior fossa due to deregulation of cerebellar development ${ }^{34)}$. In rare cases, medulloblastoma can be associated with inherited disorders such as Li-
Fraumeni, Turcot or Gorlin syndrome $e^{23,52)}$.

Integrative genomic studies from several independent research groups have shown that medulloblastoma is not a single disease but is comprised of at least four subgroups with specific demographic, genetic, transcriptional, clinical, and prognostic characteristics ${ }^{31,43,62,66,76,85,89)}$. The medulloblastoma subgroups are termed wingless (WNT), sonic hedgehog (SHH), group 3 , and group 4 and were agreed upon by experts from

- Received : February 1, 2018 •Revised : February 14, 2018 •Accepted : March 3, 2018

- Address for reprints : Michael D. Taylor, M.D., Ph.D.

The Hospital for Sick Children, 555 University Avenue, Toronto M5G 1X8, Canada

Tel : +1-416-813-6427, Fax : +1-416-813-4975, E-mail : mdtaylor@sickkids.ca

*These authors contributed equally to this work.

This is an Open Access article distributed under the terms of the Creative Commons Attribution Non-Commercial License (http://creativecommons.org/licenses/by-nc/4.0) which permits unrestricted non-commercial use, distribution, and reproduction in any medium, provided the original work is properly cited. 
around the world during a consensus meeting in Boston in $2010^{85}$.

The 5-year overall survival of medulloblastoma patients is $60-70 \%$ under the current standard multimodal treatment consisting of maximal safe tumor resection, chemotherapy and, for non-infant ( $>3-5$ years) patients, craniospinal irradiation ${ }^{20,87}$. Unfortunately, improved outcome has been associated with serious long-term treatment sequelae such as neurocognitive impairment, endocrine deficiencies, and secondary tumors ${ }^{32,39,40)}$. During the last two decades, tumor staging of medulloblastoma patients has been solely based on clinical factors (patient's age, presence or absence of metastases at diagnosis, postoperative residual tumor) and, in some studies, histopathological subtypes $^{85)}$. A recently proposed, refined risk stratification of non-infant medulloblastoma patients based on subgroup and outcome data allows a classification of patients into four groups with different prognoses : "low risk" ( $>90 \%$ survival), "standard risk” (75-90\% survival), "high risk" (50-75\% survival), and "very high risk" ( $<50 \%$ survival). This new approach to patient stratification opens the door for future clinical trials including treatment de-escalation for patients with favorable outcomes and development of urgently needed new therapies for patients with high-risk disease ${ }^{611}$.

Leptomeningeal dissemination occurs in up to $40 \%$ of patients at time of diagnosis and almost all patients present with metastases at time of recurrence ${ }^{96)}$. Despite good progress in the clinical management of patients with medulloblastoma, recurrent and metastatic disease remain incurable and metastatic relapse is the primary cause of death in children with medulloblastoma. Thus, characterization of the molecular mechanisms of metastatic spread and survival in the metastatic niche, coupled with the identification of targetable vulnerabilities in these processes is a key area of current and future investigation.

\section{MOLECULAR SUBGROUPS}

The four subgroups (WNT, SHH, group 3, and group 4) were identified based on integrated genomics studies and feature well-defined clinical, histopathological, genetic, transcriptional, and prognostic characteristics (Fig. 1) ${ }^{45,46,57,62,63,70,73,76,85,95)}$. Recent research suggests that, based on genetic, transcriptional and epigenetic data, medulloblastoma can be divided even further into molecularly-determined subtypes which may potentially improve patient stratification in future clinical trials ${ }^{6,42,50,74,75)}$.

\section{WNT}

This represents the rarest subgroup and accounts for approximately $10 \%$ of all medulloblastomas. Children and adolescents are the most commonly affected age groups ${ }^{27)}$. WNT medulloblastomas are thought to arise from progenitor cells of the dorsal brain stem in the lower rhombic lip and typically present with somatic mutations in the CTNNB1 gene which encodes beta-catenin and leads to an overexpression of the subgroup-defining WNT signaling pathway ${ }^{16,44)}$. Monosomy of chromosome 6 is characteristic of this subgroup ${ }^{42,46)}$. TP53, DDX $3 X$, and SMARCA4 mutations have also been described in patients with WNT tumors ${ }^{24,42,55,67,101)}$. WNT medulloblastomas are rarely metastatic and have a favorable outcome compared to the other subgroups ${ }^{76)}$.

\section{SHH}

A bimodal age distribution is typical for SHH tumors, with a peak incidence during infancy and adolescence ${ }^{27}$. About 30\% of all medulloblastomas are classified as $\mathrm{SHH}$ tumors which are frequently located laterally in the cerebellar hemispheres ${ }^{27,54)}$. There is evidence, that SHH medulloblastoma originates from cerebellar granule precursor cells of the external granule lay$\mathrm{er}^{8,16,44)}$. Hyperactivation of the SHH signaling pathway is characteristic of this subgroup and is often due to mutations in the tumor suppressor genes PTCH1, SMO and SUFU, or amplifications of GLI2 or MYCN ${ }^{26,84,86)}$. TP53 mutations can be found in about $20 \%$ of all patients with SHH medulloblastoma and define a "very high risk" group of patients with poor outcome $^{61,101)}$. About $20 \%$ of patients with SHH tumors present with metastases at time of diagnosis.

\section{Group 3}

This subgroup represents about $25 \%$ of all medulloblastomas and affects almost exclusively infants and children. A male predominance is typical for this highly aggressive subgroup ${ }^{27)}$. A commonly overexpressed pathway has not been identified, however, MYC amplification and isochromosome 17q are frequently observed alterations in these tumors ${ }^{76,90,99)}$. In addition, amplification of OTX2, mutation of SMARCA4 and enhancer activation of GFI1 and GFI1B are recurrent genetic alterations ${ }^{47,77)}$. Patients with group 3 tumors have the worst outcome and present with leptomeningeal dissemination at time of diagnosis in 


\begin{tabular}{|c|c|c|c|c|}
\hline & WNT & SHH & Group 3 & Group 4 \\
\hline Age group & & & & \\
\hline Gender ratio $\left(\bigcirc^{7}: \bigcirc\right)$ & $1: 1$ & $1: 1$ & $2: 1$ & $3: 1$ \\
\hline Outcome & Very good & $\begin{array}{l}\text { Infants good, others } \\
\text { intermediate }\end{array}$ & Poor & Intermediate \\
\hline Anatomic location & $\begin{array}{l}\text { Brainstem, } \\
\text { 4th ventricle }\end{array}$ & $\begin{array}{l}\text { Cerebellar } \\
\text { hemispheres }\end{array}$ & Midline, 4th ventricle & Midline, 4th ventricle \\
\hline $\begin{array}{l}\text { Metastasis at } \\
\text { diagnosis }\end{array}$ & $5-10 \%$ & $15-20 \%$ & $40-45 \%$ & $35-40 \%$ \\
\hline Pattern of recurrence & $\begin{array}{l}\text { Rare. Can be local } \\
\text { or metastatic }\end{array}$ & Local & Metastatic & Metastatic \\
\hline Genetic alterations & $\begin{array}{c}\text { CTNNB1, } \\
\text { DDX3X, } \\
\text { SMARCA4, } \\
\text { TP53 mutation }\end{array}$ & $\begin{array}{l}\text { PTCH1, SMO, } \\
\text { SUFU, TP53 } \\
\text { mutation } \\
\text { GLI2, MYCN } \\
\text { amplification }\end{array}$ & $\begin{array}{c}\text { GLI1, } \\
\text { GFL1B activation, } \\
\text { MYC, } \\
\text { OTX-2 amplification, } \\
\text { SMARCA4 mutation }\end{array}$ & $\begin{array}{l}\text { KDM6A mutation, } \\
\text { SNCAIP duplication } \\
\text { CDK6, MYCN } \\
\text { amplification }\end{array}$ \\
\hline $\begin{array}{l}\text { Cytogenetic } \\
\text { aberrations }\end{array}$ & Monosomy 6 & $\begin{array}{c}3 q \text { gain } \\
9 q, 10 q, 17 p \text { loss }\end{array}$ & $\begin{array}{c}i 17 q \\
1 q, 7,18 \text { gain } \\
10 q, 11,16 q, 17 p \text { loss }\end{array}$ & $\begin{array}{c}i 17 q \\
7 q, 18 q \text { gain } \\
8 p, 11 p, X \text { loss }\end{array}$ \\
\hline
\end{tabular}

Fig. 1. Molecular subgroups of medulloblastoma ${ }^{16,24,26,42,44,47,49,54,67,76,77,85,101)}$. WNT : wingless, $S H H$ : sonic hedgehog, $M$ : male, $F:$ female.

$40-45 \%$ of cases.

\section{Group 4}

These medulloblastomas affect patients of all age groups and account for approximately $35 \%$ of all medulloblastomas ${ }^{27)}$. Although this subgroup is the most common, the underlying pathogenesis is poorly understood and the cells of origin have not been identified. Isochromosome $17 \mathrm{q}$ can be found in almost all group 4 tumors, however, there is no association with poor outcome in contrast to that described for group 3 medulloblastomas $^{76)}$. Mutation of KDM6A, amplification of MYCN and CDK6, loss of chromosome $\mathrm{X}$ in females and duplications of SNCAIP are also frequently detected cytogenetic alterations in this subgroup ${ }^{44,49,77,79,85)}$. Despite the frequent presence of metas- tases at diagnosis, the overall outcome of patients with group 4 medulloblastoma is intermediate.

\section{RISK STRATIFICATION}

Traditionally, medulloblastoma patients have been classified into two risk groups, "average risk" and "high risk", using three clinical criteria : age at diagnosis, presence or absence of leptomeningeal dissemination (based on magnetic resonance imaging and cerebrospinal fluid [CSF] analysis), and extent of residual tumor after resection. "Average risk" patients are older than 3 years of age and present with non-metastatic disease (no macroscopic metastasis on imaging scans and no micro- 
scopic tumor cells found in CSF) and a residual tumor size $<1.5 \mathrm{~cm}^{2}$. The presence of metastases and/or a postoperative tumor size $>1.5 \mathrm{~cm}^{2}$ defines "high risk" disease ${ }^{46)}$. Infants $(<3$ years) are generally considered high risk and are treated using radiation-sparing protocols to reduce neurocognitive side effects.

During a consensus meeting in Heidelberg in 2015, a new risk stratification protocol based on molecular and prognostic criteria was proposed for patients between 3 and 17 years of age $^{60,61)}$. The refined classification has four risk groups, mainly defined by outcome, and takes disease heterogeneity and molecular subgroup information into account. The protocol defines patients as "very high risk" (<50\% survival), "high risk" (50$75 \%$ survival), "standard risk" (75-90\% survival), and "low risk" (>90\% survival ${ }^{61)}$. Patients with metastatic group 3 medulloblastoma as well as patients with TP53 mutated SHH tumors have a poor prognosis and should be considered very high risk ${ }^{58,65,80)}$. High risk patients are patients with metastatic or MYCN amplified SHH tumors as well as group 4 medullo- blastoma patients with leptomeningeal dissemination ${ }^{28,56,61)}$. Patients with non-MYCN amplified, non TP53-mutated SHH medulloblastoma, non-MYC amplified group 3 tumors and group 4 tumors without chromosome 11 loss are considered standard risk ${ }^{61)}$. Low risk are non-metastatic WNT patients as well as patients with non-metastatic group 4 tumors and whole chromosome 11 loss (Fig. 2) ${ }^{61)}$.

The new patient risk stratification allows for evaluation of treatment de-escalation for patients with favorable outcomes and improves the ability to identify and test new rational, targeted therapies in patients in "high risk" and "very high risk" groups $^{61)}$.

\section{CURRENT THERAPIES}

The current treatment protocols are largely based on the traditional risk stratification and the age of the patient at the time of diagnosis ${ }^{64)}$. Patients initially undergo tumor resection at the

\begin{tabular}{|c|c|c|c|c|}
\hline & $\begin{array}{l}\text { Low risk } \\
\text { (<90\% survival) }\end{array}$ & $\begin{array}{l}\text { Standard risk } \\
\text { (75-90\% survival) }\end{array}$ & $\begin{array}{l}\text { High risk } \\
\text { (50-75\% survival) }\end{array}$ & $\begin{array}{l}\text { Very high risk } \\
\text { ( }<50 \% \text { survival) }\end{array}$ \\
\hline WNT & Non-metastatic & & & \\
\hline SHH & & $\begin{array}{l}\text { Non-metastatic } \\
\text { AND } \\
\text { TP53 WT } \\
\text { AND } \\
\text { No MYCN amplification }\end{array}$ & $\begin{array}{l}\text { Metastatic } \\
\text { AND } \\
\text { TP53 WT } \\
\text {-- OR -- } \\
\text { Non-metastatic } \\
\text { AND } \\
\text { MYCN amplification }\end{array}$ & TP53 mutation \\
\hline Group 3 & & $\begin{array}{l}\text { Non-metastatic } \\
\text { AND } \\
\text { No MYC amplification }\end{array}$ & & $\begin{array}{l}\text { Metastatic } \\
\text { AND } \\
\text { MYC amplification }\end{array}$ \\
\hline Group 4 & $\begin{array}{l}\text { Non-metastatic } \\
\text { AND } \\
\text { Chromosome } 11 \text { loss }\end{array}$ & $\begin{array}{l}\text { Non-metastatic } \\
\text { AND } \\
\text { No chromosome } 11 \text { loss }\end{array}$ & Metastatic & \\
\hline
\end{tabular}

Fig. 2. Patient risk stratication based on molecular and outcome criteria ${ }^{611}$. WNT : wingless, SHH : sonic hedgehog, M : male, F: female. 
time of diagnosis, regardless of risk group ${ }^{29,64)}$. Recent re-analysis of the prognostic value of extent of resection with subgroup taken into account, demonstrates that there is no benefit for gross total resection over subtotal resection in overall survival for patients, regardless of subgroup, and no overall survival or progression-free survival benefit for patients who underwent near-total versus gross-total resection ${ }^{88}$. Thus, maximal safe surgical resection represents the standard of care for medulloblastoma and there is no apparent clinical benefit of surgical removal of small volume residual disease that carries a high risk of neurological morbidity ${ }^{88}$.

Subsequently, "average risk" patients over the age of 3-5 (age cutoffs vary depending on the cooperative group performing the clinical trials) are treated with 23.4 Gy craniospinal irradiation with a boost of $55 \mathrm{~Gy}$ to the tumor bed in the posterior fossa and adjuvant cytotoxic chemotherapy ${ }^{30)}$. "High risk" patients undergo craniospinal radiation using a dose of 36-39 Gy, a boost of 55 Gy to the tumor bed, and adjuvant chemothera$\mathrm{py}^{21)}$. Typical chemotherapy regimens consist of cisplatin/carboplatin-vincristine-cyclophosphamide combinations.

Infants below the age of $3-5$ years are currently treated with radiation sparing approaches because of the devastating neuro-cognitive side-effects of craniospinal radiation on the developing nervous system ${ }^{7,15,1,21,711}$. Various chemotherapy regimens have been studied, such as vincristine, cyclophosphamide, etoposide, and cisplatin followed by autologous hematopoietic cell rescue (CCG-99703) and methotrexate (intravenous and intraventricular), vincristine, cyclophosphamide, and carboplatin (HIT-SKK'92) ${ }^{7,711}$. Survival rates in patients with non-desmoplastic histology and macroscopic metastatic disease at the time of diagnosis in this age-group continue to have dismal outcomes $^{64)}$.

\section{BIOLOGICALLY INFORMED TREATMENT STRATEGIES}

The understanding of the heterogeneity that exists within tumors that are broadly classified as medulloblastoma is allowing molecularly stratified trials to be carried out based on both molecular subgroups and an improved understanding of risk stratification ${ }^{49,61}$. The advanced understanding of key molecular alterations within different subgroups (and subtypes) of medulloblastoma provides a basis for the development of risk-adapt- ed treatment protocols and novel targeted therapies specific to molecular events within a particular patient's tumor ${ }^{12,21,64,91)}$. Numerous pre-clinical and clinical trials are underway to develop and test small-molecular inhibitors, antibody-based therapies, and immunotherapies that exploit molecular vulnerabilities in these tumors ${ }^{2,10,11,21,33)}$.

\section{WNT subgroup}

A key strategy being introduced in several active phase II and phase III studies is de-escalation of first-line treatments in lowrisk (non-metastatic) WNT medulloblastoma ${ }^{21,64)}$. These trials are designed to reduce (SJMB12, PNET $5 \mathrm{MB}$ ) or eliminate craniospinal irradiation (NCT02212574) and implement reduced dose regimens of chemotherapy (PNET $5 \mathrm{MB}$ ). Given the excellent overall survival historically noted in these patients $(>90 \%)$, these studies aim to reduce treatment-related morbidity in these patients with biologically favorable outcomes ${ }^{19,59,611}$.

\section{SHH subgroup}

Numerous preclinical studies identified hedgehog signaling pathway activation in medulloblastoma and demonstrated evidence of in vitro efficacy of hedgehog pathway inhibitors in medulloblastoma ${ }^{4,68,81,82)}$. Vismodegib and sonidegib, competitive antagonists of the smoothened receptor, were among the first targeted therapies to advance to early stage clinical trials in medulloblastoma patients ${ }^{33,68)}$. Notably, adult and pediatric medulloblastoma patients treated with vismodegib (PBTC-025B and PBTC-032) exhibited improved progression free-survival in recurrent SHH medulloblastoma, but not non-SHH medulloblastoma ${ }^{68)}$. Response to smoothened (SMO) inhibition is highly dependent on the presence of Hedgehog pathway alterations downstream of SMO, including SUFU negative regulator of hedgehog signaling (SUFU) mutations and GLI family zinc finger 2 (GLI2) or MYCN amplifications, which infer resistance to SMO inhibitors ${ }^{26,51}$. SMO inhibition monotherapy has been associated with selection of treatment-resistant subclones, via novel mutations affecting SMO inhibition or upregulation of alternate survival pathways, suggesting that SMO inhibitors will need to be accompanied by additional agents to achieve a durable treatment response ${ }^{5,69,977}$.

Alternative agents targeting downstream components of the Hedgehog signaling pathway include arsenic trioxide and itraconazole, inhibitors of the GLI transcription factor, which may be effective in the subset of patients with hedgehog activation 
independent of SHH-PTCH1-SMO ${ }^{25,70,83)}$.

Further pre-clinical work has identified additional pathways that may represent targetable vulnerabilities in this subgroup ${ }^{11,35,36)}$. For example, in a functional genomic mouse model of $\mathrm{SHH}$ medulloblastoma, metastatic populations were enriched for clones with PI3K pathway insertions, suggesting this pathway may be an essential pathway for SHH medulloblastoma metastasis $^{41,78,96)}$. Recurrent TP53 mutations are observed in a subtype of SHH medulloblastomas and may represent another targetable pathway to overcome the radiation resistance associated with these mutations ${ }^{80,100)}$. Further pre-clinical work is necessary to clarify the ideal candidate therapies and drug combinations to be tested in the next generation of clinical trials.

\section{Group 3 and group 4}

Group 3 and 4 tumors currently lack specific targeted therapies in existing clinical trials. However, trial SJMB12 contains a treatment arm for high risk patients, defined as those with metastases at diagnosis, incomplete resection, and/or MYC or MYCN amplified, which will be treated with an additional, novel combination of cytotoxic chemotherapy agents (pemetrexed and gemcitabine $)^{21}$. However, no current clinical trials exclusively enrolling medulloblastoma patients are investigating targeted therapies in these subgroups. Patients with group 3 medulloblastoma currently have the worst prognosis and need to be prioritized for novel treatments ${ }^{10)}$.

Group 3 and group 4 tumors appear to demonstrate heterogeneity in terms of activated signaling pathways, with MYC amplification being the most common cytogenetic alteration in group 3 tumors ${ }^{53,92}$. Promising pre-clinical agents in group 3 $M Y C$-driven medulloblastoma include combination treatment using PI3K and histone deacetylase inhibitors and BET-bromodomain inhibitors ${ }^{3,53}$. Epigenetic alterations are common in these subgroups, meaning epigenetic targeting may be a promising area for further preclinical investigation ${ }^{1,922,33,48)}$.

\section{METASTATIC MEDULLOBLASTOMA}

Medulloblastoma typically metastasizes to the leptomeninges and disseminated leptomeningeal disease represents a formidable treatment challenge. The incidence of metastasis in medulloblastoma at diagnosis is approximately $40 \%$ across all subgroups, although each subgroup varies in terms of frequen- cy at diagnosis (Fig. 1) ${ }^{96,98)}$. The presence of metastatic disease at the time of diagnosis is a poor prognostic sign in non-WNT subgroups of medulloblastoma ${ }^{61)}$.

Given the near-universal treatment failure encountered in the setting of relapsed metastatic disease the treatment of the metastatic compartment is now a key focus of investigation ${ }^{64}$. An essential discovery has been that medulloblastoma undergoes significant clonal selection and evolution during the course of the disease, meaning that tumor cells from the metastatic compartment harbor unique genetic and epigenetic alterations not present in the primary tumor ${ }^{37,93)}$. Evidence for this includes integrated genomic profiling (copy number, DNA methylation, and whole exome sequencing) of matched tumors from primary and metastatic tumors from human patients and supportive data from a murine transposon-driven SHH-medulloblastoma model, in which common transposon insertion sites were significantly different between the primary and metastatic tumors ${ }^{37,96)}$. Thus, metastatic medulloblastoma cells are dependent on molecular pathways for survival in the metastatic niche that are different from the primary tumor, and will likely require specific targeted treatment ${ }^{37}$. Pre-clinical work in this area should focus on identifying mechanisms of medulloblastoma metastasis, while future clinical trials need to account for the unique molecular profile of metastatic medulloblastoma; biopsy of the metastatic compartment to confirm the presence of a treatment target may be necessary to optimize patient selection for experimental therapies.

\section{RECURRENT MEDULLOBLASTOMA}

Recurrent medulloblastoma remains extremely refractory to existing therapies, with response rates to various treatment approaches (repeat surgery, re-irradiation, additional chemotherapy regimens, and targeted therapies) at relapse under $10 \%{ }^{13,64,72}$. Recent studies have provided significant advances in our understanding of clonal selection events in medulloblastoma from the time of initial diagnosis to recurrence, which is important for biologically informed design of future clinical trials ${ }^{38}$.

Tumors of each subgroup have a predilection for specific patterns of spatial and temporal recurrence ${ }^{37,38,62)}$. WNT tumors recur in both the primary tumor site and the metastatic compartment, although recurrence rates in this subgroup are low $^{62}$. SHH tumors have a predilection for local recurrence, while group 3 
and 4 tumors typically recur with metastatic dissemination ${ }^{62)}$. Functional genomic mouse models combined with sequencing of human primary and recurrent samples have demonstrated that the dominant clone at recurrence is present as a minor clone in the primary tumor, and that treatment pressures induce clonal selection and evolution, and lead to the acquisition of novel somatic mutations not present in the primary tumor $^{38,96)}$. Design of future clinical trials for recurrent disease should recognize this process and base decisions on resampling and profiling of the recurrent tumor, for proper patient selection for novel therapies.

\section{FUTURE DIRECTIONS}

A refined understanding of the molecular underpinnings of medulloblastoma offer significant promise to improve survival of patients with medulloblastoma, and reduce treatment related adverse events, particularly in low risk subgroups. Current work is focusing on defining the heterogeneity within tumor subgroups, this has been most recently demonstrated by multiple groups proposing a refined classification system that identifies new subtypes within each subgroup ${ }^{6,42,74)}$. These subtypes can provide further clarity in terms of recurrent molecular alterations and could aid in improved selection of patients for targeted therapies, however, there is currently no defined consensus definition of medulloblastoma subtypes.

Significant challenges remain in translating these findings to realize clinical benefit ${ }^{18)}$. Accrual of sufficient patients for a clinical trial in medulloblastoma requires multicenter collaboration, and this challenge will be intensified as patients with particular genetic alterations are recruited for trials with targeted therapies ${ }^{94)}$. International collaboration will be necessary to determine the ideal design and goals of future clinical trials, to maximize the translation of advances in the molecular understanding of this cancer into improved survival and quality of life for medulloblastoma patients. Neurosurgeons have an important role to play in these endeavors, and given the spatial heterogeneity and evolution of medulloblastoma from the time of treatment to recurrence, biopsies of metastatic and recurrent tumors will likely be necessary to effectively match patients to an optimal targeted therapy.

\section{CONFLICTS OF INTEREST}

No potential conflict of interest relevant to this article was reported.

\section{INFORMED CONSENT}

This type of study does not require informed consent.

\section{- Acknowledgements}

The authors would like to thank Stacey Krumholtz, Medical Illustrator at The Hospital for Sick Children, Toronto, for the design of the tables and Dr. Craig Daniels Ph.D. for editing the manuscript.

\section{References}

1. Alimova I, Venkataraman S, Harris P, Marquez VE, Northcott PA, Dubuc A, et al. : Targeting the enhancer of zeste homologue 2 in medulloblastoma. Int J Cancer 131 : 1800-1809, 2012

2. Badodi S, Dubuc A, Zhang X, Rosser G, Da Cunha Jaeger M, KamedaSmith MM, et al. : Convergence of BMI1 and CHD7 on ERK signaling in medulloblastoma. Cell Rep 21 : 2772-2784, 2017

3. Bandopadhayay P, Bergthold G, Nguyen B, Schubert S, Gholamin S, Tang $Y$, et al. : BET bromodomain inhibition of MYC-amplified medulloblastoma. Clin Cancer Res 20 : 912-925, 2014

4. Berman DM, Karhadkar SS, Hallahan AR, Pritchard Jl, Eberhart CG, Watkins DN, et al. : Medulloblastoma growth inhibition by hedgehog pathway blockade. Science 297 : 1559-1561, 2002

5. Buonamici S, Williams J, Morrissey M, Wang A, Guo R, Vattay A, et al. : Interfering with resistance to smoothened antagonists by inhibition of the PI3K pathway in medulloblastoma. Sci TransI Med 2 : 51ra70, 2010

6. Cavalli FMG, Remke M, Rampasek L, Peacock J, Shih DJH, Luu B, et al. : Intertumoral heterogeneity within medulloblastoma subgroups. Cancer Cell 31 : 737-754.e6, 2017

7. Cohen BH, Geyer JR, Miller DC, Curran JG, Zhou T, Holmes E, et al. : Pilot study of intensive chemotherapy with peripheral hematopoietic cell support for children less than 3 years of age with malignant brain tumors, the CCG-99703 phase I/II study. a report from the Children's Oncology Group. Pediatr Neurol 53 : 31-46, 2015

8. Dubuc AM, Northcott PA, Kenney AM, Taylor MD : Calculating a cure for cancer: managing medulloblastoma MATH1-ematically. Expert Rev Neurother $10: 1489-1492,2010$

9. Dubuc AM, Remke M, Korshunov A, Northcott PA, Zhan SH, MendezLago $M$, et al. : Aberrant patterns of H3K4 and H3K27 histone lysine methylation occur across subgroups in medulloblastoma. Acta Neuro- 
pathol $125: 373-384,2013$

10. Faria CC, Agnihotri S, Mack SC, Golbourn BJ, Diaz RJ, Olsen S, et al. : Identification of alsterpaullone as a novel small molecule inhibitor to target group 3 medulloblastoma. Oncotarget 6 : 21718-21729, 2015

11. Faria CC, Golbourn BJ, Dubuc AM, Remke M, Diaz RJ, Agnihotri S, et al. : Foretinib is effective therapy for metastatic sonic hedgehog medulloblastoma. Cancer Res 75 : 134-146, 2015

12. Gajjar A, Pfister SM, Taylor MD, Gilbertson RJ : Molecular insights into pediatric brain tumors have the potential to transform therapy. Clin Cancer Res 20 : 5630-5640, 2014

13. Gajjar A, Pizer B : Role of high-dose chemotherapy for recurrent medulloblastoma and other CNS primitive neuroectodermal tumors. Pediatr Blood Cancer 54 : 649-651, 2010

14. Gajjar AJ, Robinson GW : Medulloblastoma-translating discoveries from the bench to the bedside. Nat Rev Clin Oncol 11 : 714-722, 2014

15. Geyer JR, Sposto R, Jennings M, Boyett JM, Axtell RA, Breiger D, et al. : Multiagent chemotherapy and deferred radiotherapy in infants with malignant brain tumors: a report from the Children's Cancer Group. J Clin Oncol 23 : 7621-7631, 2005

16. Gibson P, Tong Y, Robinson G, Thompson MC, Currle DS, Eden C, et al. : Subtypes of medulloblastoma have distinct developmental origins. Nature 468 : 1095-1099, 2010

17. Grill J, Sainte-Rose C, Jouvet A, Gentet JC, Lejars O, Frappaz D, et al. : Treatment of medulloblastoma with postoperative chemotherapy alone: an SFOP prospective trial in young children. Lancet Oncol 6 : 573-580, 2005

18. Guerreiro Stucklin AS, Ramaswamy V, Daniels C, Taylor MD : Review of molecular classification and treatment implications of pediatric brain tumors. Curr Opin Pediatr 30 : 3-9, 2018

19. Henrich N, Marra CA, Gastonguay L, Mabbott D, Malkin D, Fryer C, et al. : De-escalation of therapy for pediatric medulloblastoma: trade-offs between quality of life and survival. Pediatr Blood Cancer 61 : 13001304, 2014

20. Hoff von K, Hinkes B, Gerber NU, Deinlein F, Mittler U, Urban C, et al. : Long-term outcome and clinical prognostic factors in children with medulloblastoma treated in the prospective randomised multicentre trial HIT'91. Eur J Cancer 45 : 1209-1217, 2009

21. Holgado BL, Guerreiro Stucklin A, Garzia L, Daniels C, Taylor MD : Tailoring medulloblastoma treatment through genomics: making a change, one subgroup at a time. Annu Rev Genomics Hum Genet 18 : 143-166, 2017

22. Hovestadt V, Jones DT, Picelli S, Wang W, Kool M, Northcott PA, et al. : Decoding the regulatory landscape of medulloblastoma using DNA methylation sequencing. Nature $510:$ 537-541, 2014

23. Johansson G, Andersson U, Melin B : Recent developments in brain tumor predisposing syndromes. Acta Oncol 55 : 401-411, 2016

24. Jones DTW, Jäger $N$, Kool M, Zichner T, Hutter B, Sultan $M$, et al. : Dissecting the genomic complexity underlying medulloblastoma. Nature 488 : 100-105, 2012

25. Kim J, Aftab BT, Tang JY, Kim D, Lee AH, Rezaee M, et al. : Itraconazole and arsenic trioxide inhibit hedgehog pathway activation and tumor growth associated with acquired resistance to smoothened antagonists.

Cancer Cell $23:$ 23-34, 2013

26. Kool M, Jones DT, Jäger $N$, Northcott PA, Pugh TJ, Hovestadt $V$, et al. : Genome sequencing of $\mathrm{SHH}$ medulloblastoma predicts genotype-related response to smoothened inhibition. Cancer Cell 25 : 393-405, 2014

27. Kool M, Korshunov A, Remke M, Jones DT, Schlanstein M, Northcott PA, et al. : Molecular subgroups of medulloblastoma: an international metaanalysis of transcriptome, genetic aberrations, and clinical data of WNT, SHH, group 3, and group 4 medulloblastomas. Acta Neuropathol 123 : 473-484, 2012

28. Korshunov A, Remke M, Kool M, Hielscher T, Northcott PA, Williamson D, et al. : Biological and clinical heterogeneity of MYCN-amplified medulloblastoma. Acta Neuropathol 123 : 515-527, 2012

29. Kuzan-Fischer CM, Guerreiro Stucklin AS, Taylor MD : Advances in genomics explain medulloblastoma behavior at the bedside. Neurosurgery 64(CN_suppl_1) : 21-26, 2017

30. Lafay-Cousin L, Smith A, Chi SN, Wells E, Madden J, Margol A, et al. : Clinical, pathological, and molecular characterization of infant medulloblastomas treated with sequential high-dose chemotherapy. Pediatr Blood Cancer 63 : 1527-1534, 2016

31. Lau J, Schmidt C, Markant SL, Taylor MD, Wechsler-Reya RJ, Weiss WA : Matching mice to malignancy: molecular subgroups and models of medulloblastoma. Childs Nerv Syst 28 : 521-532, 2012

32. Law N, Smith ML, Greenberg M, Bouffet E, Taylor MD, Laughlin S, et al. : Executive function in paediatric medulloblastoma: the role of cerebrocerebellar connections. J Neuropsychol 11 : 174-200, 2017

33. MacDonald TJ, Aguilera D, Castellino RC : The rationale for targeted therapies in medulloblastoma. Neuro Oncol 16 : 9-20, 2014

34. Marino S : Medulloblastoma: developmental mechanisms out of control. Trends Mol Med $11:$ 17-22, 2005

35. Milla LA, Arros A, Espinoza N, Remke M, Kool M, Taylor MD, et al. : Neogenin1 is a sonic hedgehog target in medulloblastoma and is necessary for cell cycle progression. Int J Cancer 134 : 21-31, 2014

36. Mille F, Tamayo-Orrego L, Levesque M, Remke M, Korshunov A, Cardin J, et al. : The Shh receptor Boc promotes progression of early medulloblastoma to advanced tumors. Dev Cell 31 : 34-47, 2014

37. Morrissy AS, Cavalli FMG, Remke M, Ramaswamy V, Shih DJH, Holgado $\mathrm{BL}$, et al. : Spatial heterogeneity in medulloblastoma. Nat Genet 49 : 780-788, 2017

38. Morrissy AS, Garzia L, Shih DJ, Zuyderduyn S, Huang X, Skowron P, et al. : Divergent clonal selection dominates medulloblastoma at recurrence. Nature 529 : 351-357, 2016

39. Moxon-Emre I, Bouffet E, Taylor MD, Laperriere N, Scantlebury N, Law N, et al. : Impact of craniospinal dose, boost volume, and neurologic complications on intellectual outcome in patients with medulloblastoma. J Clin Oncol 32 : 1760-1768, 2014

40. Moxon-Emre I, Taylor MD, Bouffet E, Hardy K, Campen CJ, Malkin D, et al. : Intellectual outcome in molecular subgroups of medulloblastoma. J Clin Oncol 34 : 4161-4170, 2016

41. Mumert M, Dubuc A, Wu X, Northcott PA, Chin SS, Pedone CA, et al. : Functional genomics identifies drivers of medulloblastoma dissemination. 
Cancer Res 72 : 4944-4953, 2012

42. Northcott PA, Buchhalter I, Morrissy AS, Hovestadt V, Weischenfeldt J, Ehrenberger $\mathrm{T}$, et al. : The whole-genome landscape of medulloblastoma subtypes. Nature $547:$ 311-317, 2017

43. Northcott PA, Dubuc AM, Pfister S, Taylor MD : Molecular subgroups of medulloblastoma. Expert Rev Neurother 12 : 871-884, 2012

44. Northcott PA, Jones DT, Kool M, Robinson GW, Gilbertson RJ, Cho YJ, et al. : Medulloblastomics: the end of the beginning. Nat Rev Cancer 12 : 818-834, 2012

45. Northcott PA, Korshunov A, Pfister SM, Taylor MD : The clinical implications of medulloblastoma subgroups. Nat Rev Neurol 8 : 340-351, 2012

46. Northcott PA, Korshunov A, Witt H, Hielscher T, Eberhart CG, Mack S, et al. : Medulloblastoma comprises four distinct molecular variants. J Clin Oncol 29 : 1408-1414, 2011

47. Northcott PA, Lee C, Zichner T, Stütz AM, Erkek S, Kawauchi D, et al. : Enhancer hijacking activates GFI1 family oncogenes in medulloblastoma. Nature 511 : 428-434, 2014

48. Northcott PA, Nakahara Y, Wu X, Feuk L, Ellison DW, Croul S, et al. : Multiple recurrent genetic events converge on control of histone lysine methylation in medulloblastoma. Nat Genet 41 : 465-472, 2009

49. Northcott PA, Shih DJ, Peacock J, Garzia L, Morrissy AS, Zichner T, et al. : Subgroup-specific structural variation across 1,000 medulloblastoma genomes. Nature $488:$ 49-56, 2012

50. Northcott PA, Shih DJ, Remke M, Cho YJ, Kool M, Hawkins C, et al. : Rapid, reliable, and reproducible molecular sub-grouping of clinical medulloblastoma samples. Acta Neuropathol 123 : 615-626, 2012

51. Pambid MR, Berns R, Adomat HH, Hu K, Triscott J, Maurer N, et al. : Overcoming resistance to Sonic hedgehog inhibition by targeting $p 90$ ribosomal $\$ 6$ kinase in pediatric medulloblastoma. Pediatr Blood Cancer $61: 107-115,2014$

52. Parsons DW, Li M, Zhang X, Jones S, Leary RJ, Lin JC, et al. : The genetic landscape of the childhood cancer medulloblastoma. Science 331 : 435-439, 2011

53. Pei Y, Liu KW, Wang J, Garancher A, Tao R, Esparza LA, et al. : HDAC and PI3K antagonists cooperate to inhibit growth of MYC-driven medulloblastoma. Cancer Cell 29 : 311-323, 2016

54. Perreault S, Ramaswamy V, Achrol AS, Chao K, Liu TT, Shih D, et al. : MRI surrogates for molecular subgroups of medulloblastoma. AJNR Am J Neuroradiol 35 : 1263-1269, 2014

55. Pfaff E, Remke M, Sturm D, Benner A, Witt H, Milde T, et al. : TP53 mutation is frequently associated with CTNNB1 mutation or MYCN amplification and is compatible with long-term survival in medulloblastoma. J Clin Oncol 28 : 5188-5196, 2010

56. Pietsch $T$, Schmidt R, Remke M, Korshunov A, Hovestadt $V$, Jones DT, et al. : Prognostic significance of clinical, histopathological, and molecular characteristics of medulloblastomas in the prospective HIT2000 multicenter clinical trial cohort. Acta Neuropathol 128 : 137-149, 2014

57. Pugh TJ, Weeraratne SD, Archer TC, Pomeranz Krummel DA, Auclair $D$, Bochicchio J, et al. : Medulloblastoma exome sequencing uncovers subtype-specific somatic mutations. Nature 488 : 106-110, 2012

58. Ramaswamy V, Nör C, Taylor MD : p53 and Meduloblastoma. Cold Spring
Harb Perspect Med 6 : a026278, 2015

59. Ramaswamy V, Northcott PA, Taylor MD : FISH and chips: the recipe for improved prognostication and outcomes for children with medulloblastoma. Cancer Genet 204 : 577-588, 2011

60. Ramaswamy V, Remke M, Adamski J, Bartels U, Tabori U, Wang X, et al. : Medulloblastoma subgroup-specific outcomes in irradiated children: who are the true high-risk patients? Neuro Oncol 18 : 291-297, 2016

61. Ramaswamy V, Remke M, Bouffet E, Bailey S, Clifford SC, Doz F, et al. : Risk stratification of childhood medulloblastoma in the molecular era: the current consensus. Acta Neuropathol 131 : 821-831, 2016

62. Ramaswamy V, Remke M, Bouffet E, Faria CC, Perreault S, Cho YJ, et al. : Recurrence patterns across medulloblastoma subgroups: an integrated clinical and molecular analysis. Lancet Oncol 14 : 1200-1207, 2013

63. Ramaswamy V, Remke M, Shih D, Wang X, Northcott PA, Faria CC, et al. : Duration of the pre-diagnostic interval in medulloblastoma is subgroup dependent. Pediatr Blood Cancer 61 : 1190-1194, 2014

64. Ramaswamy V, Taylor MD : Medulloblastoma: from myth to molecular. J Clin Oncol 35 : 2355-2363, 2017

65. Rausch T, Jones DT, Zapatka M, Stütz AM, Zichner T, Weischenfeldt J, et al. : Genome sequencing of pediatric medulloblastoma links catastrophic DNA rearrangements with TP53 mutations. Cell 148 : 59-71, 2012

66. Remke M, Hielscher T, Northcott PA, Witt H, Ryzhova M, Wittmann A, et al. : Adult medulloblastoma comprises three major molecular variants. J Clin Oncol 29 : 2717-2723, 2011

67. Robinson G, Parker M, Kranenburg TA, Lu C, Chen X, Ding L, et al. : Novel mutations target distinct subgroups of medulloblastoma. Nature 488 : 43-48, 2012

68. Robinson GW, Orr BA, Wu G, Gururangan S, Lin T, Qaddoumi I, et al. : Vismodegib exerts targeted efficacy against recurrent sonic hedgehogsubgroup medulloblastoma: results from phase II Pediatric Brain Tumor Consortium studies PBTC-025B and PBTC-032. J Clin Oncol 33 : 26462654, 2015

69. Rudin CM, Hann CL, Laterra J, Yauch RL, Callahan CA, Fu L, et al. : Treatment of medulloblastoma with hedgehog pathway inhibitor GDC-0449.

N Engl J Med 361 : 1173-1178, 2009

70. Rusert JM, Wu X, Eberhart CG, Taylor MD, Wechsler-Reya RJ : SnapShot: medulloblastoma. Cancer Cell 26 : 940-940.e1, 2014

71. Rutkowski S, Bode U, Deinlein F, Ottensmeier H, Warmuth-Metz M, Soerensen $\mathrm{N}$, et al. : Treatment of early childhood medulloblastoma by postoperative chemotherapy alone. N Engl J Med 352 : 978-986, 2005

72. Sabel M, Fleischhack G, Tippelt S, Gustafsson G, Doz F, Kortmann R, et al. : Relapse patterns and outcome after relapse in standard risk medulIoblastoma: a report from the HIT-SIOP-PNET4 study. J Neurooncol 129 : 515-524, 2016

73. Schneider C, Ramaswamy V, Kulkarni AV, Rutka JT, Remke M, Tabori U, et al. : Clinical implications of medulloblastoma subgroups: incidence of CSF diversion surgery. J Neurosurg Pediatr 15 : 236-242, 2015

74. Schwalbe EC, Lindsey JC, Nakjang S, Crosier S, Smith AJ, Hicks D, et al. : Novel molecular subgroups for clinical classification and outcome prediction in childhood medulloblastoma: a cohort study. Lancet Oncol 18 : 958-971, 2017 
75. Schwalbe EC, Williamson D, Lindsey JC, Hamilton D, Ryan SL, Megahed $\mathrm{H}$, et al. : DNA methylation profiling of medulloblastoma allows robust subclassification and improved outcome prediction using formalin-fixed biopsies. Acta Neuropathol 125 : 359-371, 2013

76. Shih DJ, Northcott PA, Remke M, Korshunov A, Ramaswamy V, Kool M, et al. : Cytogenetic prognostication within medulloblastoma subgroups. J Clin Oncol 32 : 886-896, 2014

77. Skowron P, Ramaswamy V, Taylor MD : Genetic and molecular alterations across medulloblastoma subgroups. J Mol Med (Berl) 93 : 1075-1084, 2015

78. Suryo Rahmanto A, Savov V, Brunner A, Bolin S, Weishaupt $H$, Malyukova $A$, et al. : FBW7 suppression leads to SOX9 stabilization and increased malignancy in medulloblastoma. EMBO J 35 : 2192-2212, 2016

79. Swartling FJ, Grimmer MR, Hackett CS, Northcott PA, Fan QW, Goldenberg $\mathrm{DD}$, et al. : Pleiotropic role for MYCN in medulloblastoma. Genes Dev 24 : 1059-1072, 2010

80. Tabori U, Baskin B, Shago M, Alon N, Taylor MD, Ray PN, et al. : Universal poor survival in children with medulloblastoma harboring somatic TP53 mutations. J Clin Oncol 28 : 1345-1350, 2010

81. Taipale J, Chen JK, Cooper MK, Wang B, Mann RK, Milenkovic L, et al. : Effects of oncogenic mutations in smoothened and patched can be reversed by cyclopamine. Nature 406 : 1005-1009, 2000

82. Taipale J, Cooper MK, Maiti T, Beachy PA : Patched acts catalytically to suppress the activity of smoothened. Nature 418 : 892-897, 2002

83. Tang Y, Gholamin S, Schubert S, Willardson MI, Lee A, Bandopadhayay P, et al. : Epigenetic targeting of hedgehog pathway transcriptional output through BET bromodomain inhibition. Nat Med 20 : 732-740, 2014

84. Taylor MD, Liu L, Raffel C, Hui CC, Mainprize TG, Zhang X, et al. : Mutations in SUFU predispose to medulloblastoma. Nat Genet 31 : 306310, 2002

85. Taylor MD, Northcott PA, Korshunov A, Remke M, Cho YJ, Clifford SC, et al. : Molecular subgroups of medulloblastoma: the current consensus. Acta Neuropathol 123 : 465-472, 2012

86. Taylor MD, Zhang X, Liu L, Hui CC, Mainprize TG, Scherer SW, et al. : Failure of a medulloblastoma-derived mutant of SUFU to suppress WNT signaling. Oncogene 23 : 4577-4583, 2004

87. Taylor RE, Bailey CC, Robinson KJ, Weston CL, Walker DA, Ellison D, et al. : Outcome for patients with metastatic (M2-3) medulloblastoma treated with SIOP/UKCCSG PNET-3 chemotherapy. Eur J Cancer 41 : 727-734, 2005

88. Thompson EM, Hielscher T, Bouffet E, Remke M, Luu B, Gururangan S, et al. : Prognostic value of medulloblastoma extent of resection after accounting for molecular subgroup: a retrospective integrated clinical and molecular analysis. Lancet Oncol 17 : 484-495, 2016

89. Thompson MC, Fuller C, Hogg TL, Dalton J, Finkelstein D, Lau CC, et al. :
Genomics identifies medulloblastoma subgroups that are enriched for specific genetic alterations. J Clin Oncol 24 : 1924-1931, 2006

90. Traenka C, Remke M, Korshunov A, Bender S, Hielscher T, Northcott PA, et al. : Role of LIM and SH3 protein 1 (LASP1) in the metastatic dissemination of medulloblastoma. Cancer Res 70 : 8003-8014, 2010

91. Triscott J, Lee C, Foster C, Manoranjan B, Pambid MR, Berns R, et al. : Personalizing the treatment of pediatric medulloblastoma: polo-like kinase 1 as a molecular target in high-risk children. Cancer Res 73 : 6734-6744, 2013

92. Venkataraman S, Alimova I, Balakrishnan I, Harris P, Birks DK, Griesinger $A$, et al. : Inhibition of BRD4 attenuates tumor cell self-renewal and suppresses stem cell signaling in MYC driven medulloblastoma. Oncotarget 5 : 2355-2371, 2014

93. Wang X, Dubuc AM, Ramaswamy V, Mack S, Gendoo DMA, Remke M, et al. : Medulloblastoma subgroups remain stable across primary and metastatic compartments. Acta Neuropathol 129 : 449-457, 2015

94. Wang X, Ramaswamy V, Remke M, Mack SC, Dubuc AM, Northcott PA, et al. : Intertumoral and intratumoral heterogeneity as a barrier for effective treatment of medulloblastoma. Neurosurgery 60 Suppl $1: 57-63$, 2013

95. Whittier KL, Boese EA, Gibson-Corley KN, Kirby PA, Darbro BW, Qian Q, et al. : G-protein coupled receptor expression patterns delineate medulloblastoma subgroups. Acta Neuropathol Commun 1 : 66, 2013

96. Wu X, Northcott PA, Dubuc A, Dupuy AJ, Shih DJ, Witt H, et al. : Clonal selection drives genetic divergence of metastatic medulloblastoma. Nature 482 : 529-533, 2012

97. Yauch RL, Dijkgraaf GJP, Alicke B, Januario T, Ahn CP, Holcomb T, et al. : Smoothened mutation confers resistance to a hedgehog pathway inhibitor in medulloblastoma. Science 326 : 572-574, 2009

98. Zapotocky M, Mata-Mbemba D, Sumerauer D, Liby P, Lassaletta A, Zamecnik J, et al. : Differential patterns of metastatic dissemination across medulloblastoma subgroups. J Neurosurg Pediatr, 2017 [Epub ahead of print]

99. Zhou L, Picard D, Ra YS, Li M, Northcott PA, Hu Y, et al. : Silencing of thrombospondin-1 is critical for myc-induced metastatic phenotypes in medulloblastoma. Cancer Res 70 : 8199-8210, 2010

100. Zhukova N, Ramaswamy V, Remke M, Martin DC, Castelo-Branco P,

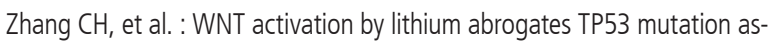
sociated radiation resistance in medulloblastoma. Acta Neuropathol Commun 2 : 174, 2014

101. Zhukova N, Ramaswamy V, Remke M, Pfaff E, Shih DJ, Martin DC, et al. : Subgroup-specific prognostic implications of TP53 mutation in medulloblastoma. J Clin Oncol 31 : 2927-2935, 2013 